Int. J. Morphol.,

33(3):1171-1175, 2015.

\title{
Output Relations of Humeral Circumflex Arteries and its Variations
}

\author{
Relaciones de las Arterias Circunflejas Humerales y sus Variaciones
}

Fontes, E. B."; Precht, B. L. C.*; Andrade R. C. L."; Fernandes R. M. P.* \& Cisne, R.*

FONTES, E. B.; PRECHT, B. L. C.; ANDRADE R. C. L.; FERNANDES R. M. P. \& CISNE, R. Output relations of humeral circumflex arteries and its variations. Int. J. Morphol., 33(3):1171-1175, 2015.

SUMMARY: A large range of variability marks the branching pattern of the axillary artery. The knowledge of the anatomical variations and this pattern is essential to diagnostic and therapeutic approaches, including surgery, of the axillary region. The aim of this study was to observe the different possible origins of circumflex humeral arteries and to measure the length and diameter of each vessel. In our study, 24 armpits from adult cadavers (fixed in tamponed formalin 10\%) were dissected. The data were analyzed with a digital caliper and the results expressed as Mean \pm SD. In majority of specimens, posterior circumflex humeral artery (PCHA) arose from subscapular artery (SSA) (54.16\%) and had an average diameter of $3.92 \pm 0.41 \mathrm{~mm}$. The anterior circumflex humeral artery was a branch from axillary artery (AA) in the majority of the specimens $(62.5 \%)$ with an average diameter of $1.83 \pm 0.68 \mathrm{~mm}$. Circumflex humeral arteries can arise from SSA, deep brachial artery and AA. The result of this study is an interesting data for origin, length and diameter of these vessels, contributing to the knowledge of these variations occurrence.

KEY WORDS: Circumflex humeral arteries; Axillary artery; Subscapular artery; Anatomical variation; Surgery.

\section{INTRODUCTION}

After the outer border of the first rib, the subclavian artery continues its trajectory as axillary artery (AA). This vessel is divided into three parts by the pectoralis minor muscle. The posterior circumflex humeral artery (PCHA) and the anterior circumflex humeral artery (ACHA) are important branches of the third part of AA.

The PCHA arises from the AA in direction to the lateral axillary space accompanied by the axillary nerve (AN), reaching the deep surface of deltoid muscle through a trajectory around the posterior aspect of the humeral surgical neck. At the same point, the ACHA arises from the AA and completes an anastomosis with the PCHA. This anastomosis is particularly relevant for vasculature of the muscles around, as well as the glenohumeral joint. The anatomy of these structures is also involved in a variety of clinical presentations, diagnostic procedures and surgical techniques. Then, the anatomy knowledge of this region is required for many medical specialties such as vascular surgery, orthopedic, radiology, anesthesiology, traumatology and reconstructive surgery (Valnicek et al., 2004; Robinson et al., 2011; Atema et al., 2012; Hagiwara et al., 2014; Kim et al., 2014).

\section{MATERIAL AND METHOD}

In our study, 24 armpits from adult cadavers were dissected in cadavers from division of human anatomy at Department of Morphology of the Fluminense Federal University. All specimens had been fixed in $10 \%$ formalin solution. The study was carried out according to the Helsinki's statement and was approved from our institutional review board.

We specifically evaluated the length and diameter of PCHA, ACHA, SSA and AA. They were analyzed regarding to their disposition in the region and the relations between them.

Data were analyzed using a digital caliper and the results were expressed as Mean $\pm \mathrm{SD}$. The distribution of continuous data was described with mean, standard deviation and minimum, median and maximum. In the case of categorical data with absolute and relative frequencies (count and percent), possible differences between groups were evaluated using an analysis of variance in the case of continuous data and a chi-square test in the case of categorical data. In case of overall significant differences as a result of ANOVA, pair-wise t-tests where evaluated using the closed

* Department of Morphology, Biomedical Center, Fluminense Federal University, Rio de Janeiro, Brazil. 
testing procedure. Box plots were used to visualize the distribution of continuous data. The level of significance was set to $5 \%$. All statistical calculations were carried out using GraphPad Prism software.

\section{RESULTS}

The PCHA was a branch of AA, as classically described, in 10 out of $24(41.6 \%)$ of the cases. In majority of specimens, PCHA arose from SSA (13 out of 24 or $54.2 \%$ ) (Fig. 1). In one single case (4.2\%), it arose from the deep brachial artery (DBA) (Fig. 2).
The ACHA was, in majority of the cases, a single branch of AA in 15 armpits (62.5\%). It was a branch of SSA in two (8.3\%) specimens and from the DBA in one (4.2\%). It arose as a common trunk (CT) with the PHCA in two cases $(8.3 \%)$. It was doubled in two cases $(8.3 \%)$. It was absent in another two cases (8.3\%).

The average diameter of each analyzed vessel was as follow: PCHA was $3.92 \pm 0.41 \mathrm{~mm}$, ACHA was $1.83 \pm 0.68 \mathrm{~mm}$ and SSA was $5.61 \pm 0.56 \mathrm{~mm}$.

When PCHA arose from SSA, the distance between the PCHA emerging from SSA origin was $22.31 \pm 5.05 \mathrm{~mm}$. Similarly, the distance between ACHA emerging from SSA origin was $20.5 \pm 17.5 \mathrm{~mm}$. The measurements of each case of PCHA arising from SSA are displayed in Table I.

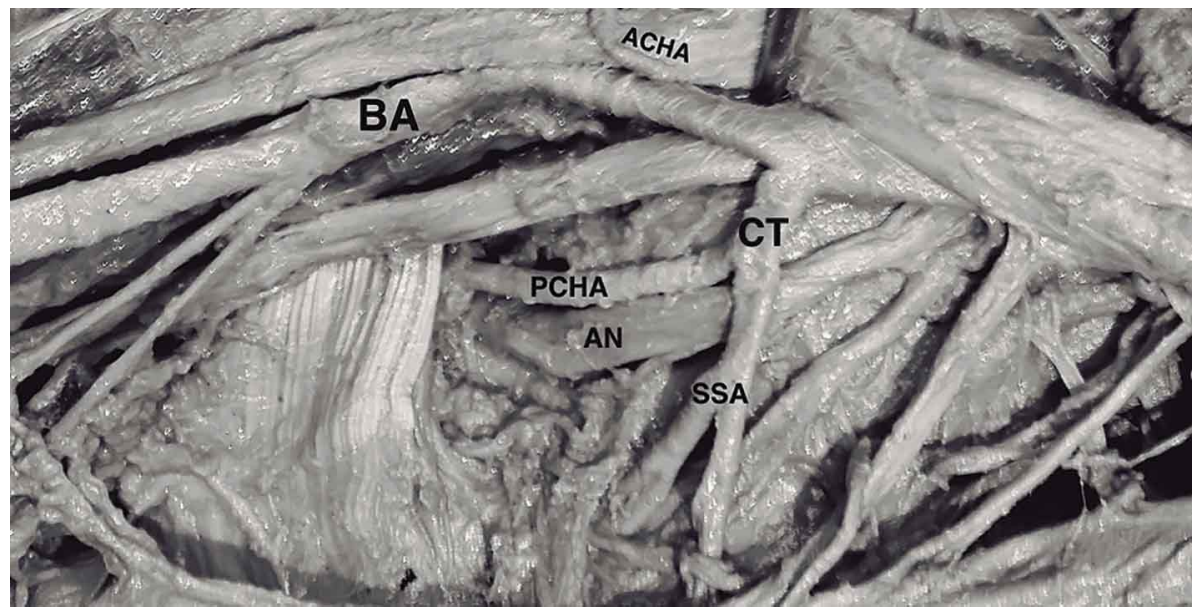

Fig. 1. Armpit from adult male cadaver shows the PCHA arising from SSA. BA= Brachial artery; $\mathrm{PCHA}=$ Posterior circunflex humeral artery; $\mathrm{AN}=$ Axillary nerve; $\mathrm{SSA}=$ Subscapular artery; $\mathrm{CT}=\mathrm{Common}$ trunk; $\mathrm{ACHA}=$ Anterior circunflex humeral artery

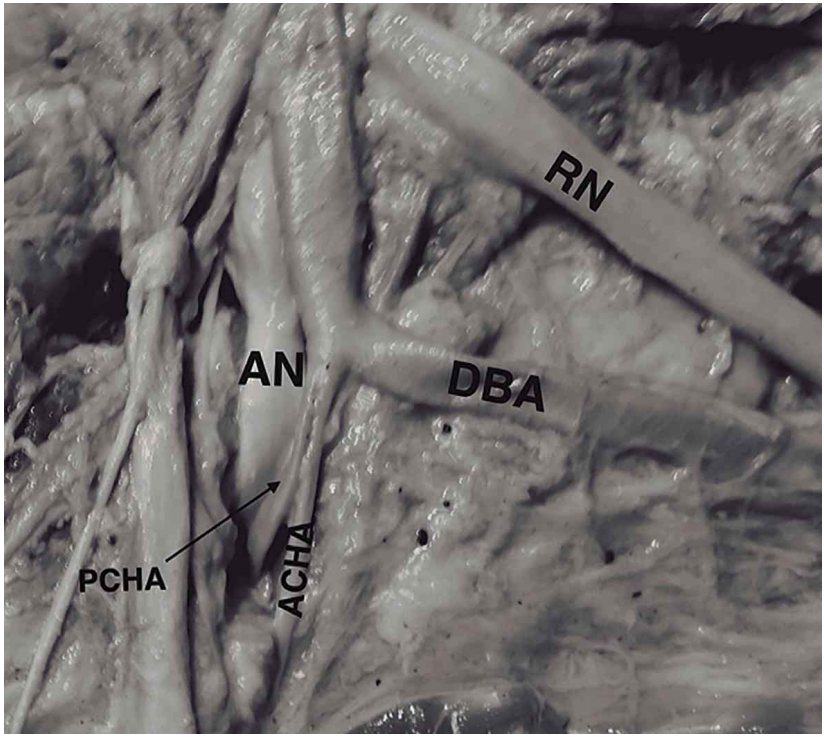

Fig. 2. Armpit from adult male cadaver shows the PCHA arising from DBA. DBA= Deep brachial artery; $\mathrm{ACHA}=$ Anterior circunflex humeral artery; $\mathrm{PCHA}=$ Posterior circunflex humeral artery; RN= Radial Nerve; $\mathrm{AN}=$ Axillary Nerve
Table I. Posterior circumflex humeral artery (PCHA) measurements when emerging from subscapular artery (SSA).

\begin{tabular}{lccc}
\hline Register & $\begin{array}{c}\text { Distance to } \\
\text { PCHA arise }\end{array}$ & SSA Diameter & PCHA Diameter \\
\hline 1 & $40 \mathrm{~mm}$ & $5 \mathrm{~mm}$ & $3 \mathrm{~mm}$ \\
2 & $5 \mathrm{~mm}$ & $4 \mathrm{~mm}$ & $3 \mathrm{~mm}$ \\
3 & $5 \mathrm{~mm}$ & $5 \mathrm{~mm}$ & $4 \mathrm{~mm}$ \\
4 & $12 \mathrm{~mm}$ & $4 \mathrm{~mm}$ & $3 \mathrm{~mm}$ \\
5 & $10 \mathrm{~mm}$ & $5 \mathrm{~mm}$ & $4 \mathrm{~mm}$ \\
6 & $45 \mathrm{~mm}$ & $6 \mathrm{~mm}$ & $6 \mathrm{~mm}$ \\
7 & $6 \mathrm{~mm}$ & $5 \mathrm{~mm}$ & $2 \mathrm{~mm}$ \\
8 & $39 \mathrm{~mm}$ & $10 \mathrm{~mm}$ & $5 \mathrm{~mm}$ \\
9 & $60 \mathrm{~mm}$ & $6 \mathrm{~mm}$ & $4 \mathrm{~mm}$ \\
10 & $21 \mathrm{~mm}$ & $7 \mathrm{~mm}$ & $5 \mathrm{~mm}$ \\
11 & $22 \mathrm{~mm}$ & $9 \mathrm{~mm}$ & $7 \mathrm{~mm}$ \\
12 & $21 \mathrm{~mm}$ & $3 \mathrm{~mm}$ & $2 \mathrm{~mm}$ \\
13 & $4 \mathrm{~mm}$ & $4 \mathrm{~mm}$ & $3 \mathrm{~mm}$ \\
\hline
\end{tabular}




\section{DISCUSSION}

Variations in the branching patterns of the major arterial trunks have been reported with an incidence of over $20 \%$ in human adult limbs (Rodríguez-Niedenfuhr et al., 2001; de Paula et al., 2013). Despite this, several variations in its origin and in the course of the AA, like other vessels of the upper limb, could be considered. A great number of references discuss the branching pattern of AA and, more specifically, the anatomy of circumflex humeral vessels.

Most part of anatomical variations are, related to embryologic disturbs. In subclavian and axillary artery variations, is important to consider the stage 16 of development $(8-11 \mathrm{~mm} ; 37 \mathrm{~d})$. In this stage, the arterial pattern shows a well-formed subclavian artery running in front of the neural plate. The neural plate is divided in anterior and posterior. The artery pierces the anterior division of the neural plate to pass between the 2 divisions. An artery remaining in front of the anterior division of the neural plate was occasionally observed. The major variation on these vessels occurs in that moment (Rodríguez-Niedenfuhr et al.).

The classical literature had a description, in which the PCHA may arise from a common trunk with the SA (15\%). The PCHA may also be a branch of the SA in $10 \%$ and the DBA in 2\% of individuals (Bergman et al., 1988; DubreuilChambardel, 1926).

Many authors described a CT for PCHA and SSA with varied frequency. De Garis \& Swartley (1928) found $1.4 \%$ of frequency, while Trotter et al. (1930) and Huelke (1959) described $13,8 \%$ and $15,2 \%$ of the cases respectively. Saeed et al. (2002) related a common origin for PCHA, ACHA and SSA in $3.8 \%$ of cases.

In Astik \& Dave (2012) study, was described a CT for PCHA, ACHA, DBA and SSA in 10\% of upper limbs and in a $15 \%$ CT for PCHA, ACHA and DBA of upper limbs. PCHA was doubled in one single case. Ramesh et al. (2008) found a CT for PCHA, ACHA, SSA, DBA and ulnar collateral arteries. Vijaya et al. (2006) reported a case of CT for PCHA, ACHA, SSA, Radial Collateral Artery, Middle and Superior Ulnar Collateral Arteries associated with the absence of DBA. Cavdar et al. (2000) related a case of PCHA, ACHA and SSA from DBA. Goldman et al. (2008) described a case of PCHA emerging from an SSA originated from a CT with the thoracoacromial artery. In this case, ACHA arose from the third part of AA. Bagoji et al. (2013) reported a case of a subscapular trunk as origin of PCHA, thoracoacromial artery and lateral thoracic artery, besides it regular branches. In this case, ACHA emerged from DBA.
Bhavya et al. (2013) described ACHA arising from PCHA in 27.2\% of left upper limbs and in $13.6 \%$ of right upper limbs in male cadavers and in $20 \%$ of both left and right upper limbs in female cadavers.

All the variations found in our study were already described with a relative frequency. Although, an unusual statistic was found: in majority of specimens, PCHA arose from SSA. Obviously, this isolated statistic is not determinant and must be analyzed with other studies as CT studies with large number of cases. However, it enabled us to perform a better evaluation of how this phenomenon happens, by using the measurements of vessels diameter and distance until PCHA origin. The study of ACHA showed a compatible correspondence to literature.

Nowadays, the knowledge of axillary anatomy is a matter of multidisciplinary approach. There are many pathologies that require a minimal familiarity with those structures and their possible variations even for diagnostic or therapeutic proposals. Regarding the circumflex arteries, this paradigm is not different.

For Orthopedics and Traumatology, PCHA and ACHA are involved in possible life-threatening vascular injuries after proximal humeral fractures (Gorthi et al., 2010), are associated with prognosis of certain kind of lesions (Papakonstantinou et al., 2012), should be considered to a better humeral fracture treatment (Meyer et al., 2005) and are a essential to the development of new surgical techniques (Gardner et al., 2006).

The strict relation between PCHA and the AN is particularly useful in the assessment of this nerve. In a pathological entity called Quadrilateral Space Syndrome, the neurovascular compression can be assessed by the visualization of PCHA occlusion and stenosis by MRI, angiography and Ultrasound (Robinson et al.). Axillary Nerve repair demands the correct identification of the structures that surround it, including PCHA (Bertelli et al., 2007). It is also a important anatomic reference for AN block in the quadrilateral space (Kim et al.).

For reconstructive surgery techniques, the circumflex vessels are useful to provide a good vascularization to flaps used in scars treatment (Vinh et al., 2009).

Besides the obvious correlation of vascular injuries due to traumatic lesions, circumflex arteries are involved in the physiopathology of many other vascular diseases. For example, the arterial injury related to the thoracic outlet syndrome is explained by the compression of the circumflex arteries and AA (Durham et al., 1995). Recently, the aneurysmatic dilation of PCHA is related as a cause of 
digital ischemia in volleyball players (van de Pol et al., 2012) and an endovascular approach is possible (Vlychou et al., 2001), reaffirming the importance of this anatomy for the endovascular techniques.

\section{CONCLUSION}

The possibility of variations in the branching of AA is enormous and it includes variations of the circumflex arteries. Many pathologies, procedures and techniques require the knowledge of this anatomy. Wellprepared professionals must be familiar to the main variation.

Our study not only described possible origins for the circumflex arteries, but also described new objective data about these vessels when in various conditions. This data contributes to the understanding and the use of these variations on the medical practice in a more precise and secure way. Obviously, this data produced represents a contribution to the literature and should be analyzed in the scientific context of axillary artery branching.

FONTES, E. B.; PRECHT, B. L. C.; ANDRADE R. C. L.; FERNANDES R. M. P. \& CISNE, R. Relaciones de las arterias circunflejas humerales y sus variaciones. Int. J. Morphol., 33(3):1171-1175, 2015.

RESUMEN: Una amplia gama de variabilidad marca el patrón de ramificación de la arteria axilar. El conocimiento de las variaciones anatómicas de este patrón es esencial para enfoques de diagnóstico y terapéuticos, incluyendo la cirugía de la región axilar. El objetivo fue observar los diferentes orígenes posibles de arterias circunflejas humerales y medir la longitud y el diámetro de cada vaso. En el estudio se disecaron 24 axilas de cadáveres adultos (fijados en formalina tamponada al 10\%). Los datos se analizaron con un calibrador digital y los resultados se expresaron como Media \pm DS. En la mayoría de los especímenes, la arteria circunfleja humeral

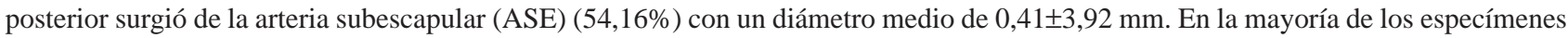
$(62,5 \%)$, la arteria circunfleja humeral anterior era una rama de la arteria axilar (AA) con un diámetro medio de $0,68 \pm 1,83 \mathrm{~mm}$. Las arterias circunflejas humerales pueden surgir de la ASE, de la arteria braquial profunda y AA. El resultado de este estudio es un dato interesante para el origen, la longitud y el diámetro de los vasos, lo que contribuye al conocimiento de la ocurrencia de estas variaciones.

PALABRAS CLAVE: Arterias circunflejas humerales; Arteria axilar; Arteria subescapular; Variación anatómica; Cirugía.

\section{REFERENCES}

Astik, R. \& Dave, U. Variations in branching pattern of the axillary artery: a study in 40 human cadavers. J. Vasc. Bras., 11(1):12-7, 2012.

Atema, J. J.; Unlü, C.; Reekers, J. A. \& Idu, M. M. Posterior circumflex humeral artery injury with distal embolisation in professional volleyball players: a discussion of three cases. Eur. J. Vasc. Endovasc. Surg., 44(2):195-8, 2012.

Bagoji, I. B.; Hadimani, G. A.; Bannur, B. M.; Patil, B. G. \& Bharatha, A. A unique branching pattern of the axillary artery: a case report. J. Clin. Diagn. Res., 7(12):2939-40, 2013.

Bergman, R. A.; Thompson, S. A.; Afifi, A. K. \& Saadeh, F. A. Compendium of Human Anatomic Variation: Catalog, Atlas and World Literature. Baltimore, Urban \& Schwarzenberg, 1988.

Bertelli, J. A.; Kechele, P. R.; Santos, M. A.; Duarte, H. \& Ghizoni, M. F. Axillary nerve repair by triceps motor branch transfer through an axillary access: anatomical basis and clinical results. J. Neurosurg., 107(2):370-7, 2007.
Bhavya, B. S.; Bhusaraddi, P. S.; Kabadi, A. M. \& Havaldhar, P. P. A morphological study on the branching pattern of subscapular artery. Anat. Karnataka, 7(1):57-62, 2013.

Cavdar, S.; Zeybek, A. \& Bayramiçli, M. Rare variation of the axillary artery. Clin. Anat., 13(1):66-8, 2000.

De Garis, C. F. \& Swartley, W. B. The axillary artery in white and negro stocks. Am. J. Anat., 41(2):353-97, 1928.

Dubreuil-Chambardel, L. Variations des Artères du Membre Superieur. Paris, Masson, 1926.

Durham, J. R.; Yao, J. S.; Pearce, W. H.; Nuber, G. M. \& McCarthy, W. J. 3rd. Arterial injuries in the thoracic outlet syndrome. J. Vasc. Surg., 21(1):57-69, 1995.

Gardner, M. J.; Voos, J. E.; Wanich, T.; Helfet, D. L. \& Lorich, D. G. Vascular implications of minimally invasive plating of proximal humerus fractures. J. Orthop. Trauma, 20(9):602-7, 2006.

Goldman, E. M.; Shah, Y. S. \& Gravante, N. A case of an extremely 
rare unilateral subscapular trunk and axillary artery variation in a male Caucasian: comparison to the prevalence within other populations. Morphologie, 96(313):23-8, 2012.

Gorthi, V.; Moon, Y. L.; Jo, S. H.; Sohn, H. M. \& Ha, S. H. Lifethreatening posterior circumflex humeral artery injury secondary to fracture-dislocation of the proximal humerus. Orthopedics, 33(3), 2010.

Hagiwara, Y.; Kanazawa, K.; Ando, A.; Nimura, A.; Watanabe, T.; Majima, K.; Akita, K. \& Itoi, E. Blood flow changes of the anterior humeral circumflex artery decrease with the scapula in internal rotation. Knee Surg. Sports Traumatol. Arthrosc., 23(5):1467-72, 2014.

Huelke, D. F. Variation in the origins of the branches of the axillary artery. Anat. Rec., 135(1):33-41, 1959.

Kim, Y. A.; Yoon, K. B.; Kwon, T. D.; Kim, D. H. \& Yoon, D. M. Evaluation of anatomic landmarks for axillary nerve block in the quadrilateral space. Acta Anaesthesiol. Scand., 58(5):567$71,2014$.

Meyer, C.; Alt, V.; Hassanin, H.; Heiss, C.; Stahl, J. P.; Giebel, G.; Koebke, J. \& Schnettler, R. The arteries of the humeral head and their relevance in fracture treatment. Surg. Radiol. Anat., 27(3):232-7, 2005.

Papakonstantinou, M. K.; Pan, W. R.; le Roux, C. M. \& Richardson, M. D. Arterial supply of the tendinous rotator cuff insertions: an anatomical study. A. N. Z. J. Surg., 82(12):928-34, 2012.

de Paula, R. C.; Erthal, R.; Fernandes, R. M. P.; Babinski, M. A.; Silva, J. G. \& Chagas, C. A. A. Anomalous origin of the deep brachial artery (profunda brachii) observed in bilateral arms: case report. J. Vasc. Bras., 12(1):53-6, 2013.

Ramesh, T. R.; Shetty, P.; Suresh, R. Abnormal branching pattern of the axillary artery and its clinical significance. Int. J. Morphol., 26(2):389-92, 2008.

Robinson, D. J.; Marks, P. \& Schneider-Kolsky, M. Occlusion and stenosis of the posterior circumflex humeral artery: detection with ultrasound in a normal population. J. Med. Imaging Radiat. Oncol., 55(5):479-84, 2011.

Rodríguez-Niedenführ, M.; Burton, G. J.; Deu, J. \& Sañudo, J. R. Development of the arterial pattern in the upper limb of staged human embryos: normal development and anatomic variations. J. Anat., 199(Pt. 4):407-17, 2001.

Saeed, M.; Rufai, A. A.; Elsayed, S. E. \& Sadiq, M. S. Variations in the subclavian-axillary arterial system. Saudi Med. J., 23(2):206-12, 2002.

Trotter, M.; Henderson, J. L.; Gass, H.; Brua, R. S.; Weisman, S.; Agress, H.; Curtis, G. H. \& Westbrook, E. R. The origins of branches of the axillary artery in whites and in American negroes. Anat. Rec., 46(2):133-7, 1930.
Valnicek, S. M.; Mosher, M.; Hopkins, J. K. \& Rockwell, W. B. The subscapular arterial tree as a source of microvascular arterial grafts. Plast. Reconstr. Surg., 113(7):2001-5, 2004.

van de Pol, D.; Kuijer, P. P.; Langenhorst, T. \& Maas, M. High prevalence of self-reported symptoms of digital ischemia in elite male volleyball players in the Netherlands: a crosssectional national survey. Am. J. Sports Med., 40(10):2296$302,2012$.

Vijaya, P. S.; Venkata, R. V.; Satheesha, N.; Mohandas, R.; Sreenivasa, R. B. \& Narendra, P. A rare variation in the branching pattern of the axillary artery. Indian J. Plast. Surg., 39(2):222-3, 2006.

Vinh, V. Q.; Van Anh, T.; Ogawa, R. \& Hyakusoku, H. Anatomical and clinical studies of the supraclavicular flap: analysis of 103 flaps used to reconstruct neck scar contractures. Plast. Reconstr. Surg., 123(5):1471-80, 2009.

Vlychou, M.; Spanomichos, G.; Chatziioannou, A.; Georganas, M. \& Zavras, G. M. Embolisation of a traumatic aneurysm of the posterior circumflex humeral artery in a volleyball player. $B r$. J. Sports Med., 35(2):136-7, 2001.

\section{Correspondence to:}

Prof. Rafael Cisne de Paula

Departamento de Morfologia - Instituto Biomédico - UFF

Rua: Prof. Ernani Melo 101, (Anatomia), São Domingos 24210-150 - Niterói (RJ)

BRAZIL

Email: rafael.cisne@gmail.com

Received: 17-11-2014

Accepted: 28-07-2015 